\title{
LUCRO DISTRIBUÍVEL
}

\author{
Autor: José Gilberto Jaloretto \\ Mestre e Doutorando em Contabilidade e \\ Controladoria no Departamento de Contabilidade e Atuaria da \\ Faculdade de Economia Administração e Contabilidade da USP
}

\section{INTRODUÇAO}

A decisão de distribuir lucros implica também na decisão de dispor de ativos, o que significa diminuir a riqueza corrente da empresa, tornando de grande importância esse momento.

$\mathrm{Na}$ determinação do valor dessa distribuição, a Contabilidade deve contribuir de forma relevante calculando e apresentando parâmetros que indiquem o valor máximo que poderia ser distribuído sem a redução do capital da empresa e preservando a sua continuidade.

Assim, a construção das informações que servirão de base à decisão de quanto distribuir deve permitir a avaliação da forma de se preservar a manutenção da riqueza ou do capital investido e conseqüentemente a continuidade da Empresa.

Nesse sentido a estruturação de qualquer estudo sobre a distribuição de lucros deve abordar os vários aspectos conceituais de lucro e sua mensuração, conceituação de lucro distribuível e manutenção de capital nas suas versões monetária e física como também e, principalmente, os aspectos relacionados à evidenciação contábil das flutuações de preços, a começar pela obra de Edgard O. Edwards e Philip W. Bell, no livro "The Theory and Measurement of Business Income", editada em 1961 pela University of California Press.

No Brasil o primeiro trabalho acadêmico que discutiu os aspectos envolvidos na evidenciação dos efeitos inflacionários surgiu em 1966 com a tese de doutoramento de Sergio de ludícibus com o titulo "Contribuição à Teoria dos Ajustamentos Contábeis" apresentada à Faculdade de Economia, Administração e Contabilidade da USP. A partir desse trabalho vários outros contribuíram para o aprofundamento do estudo iniciado com a obra de Edwards \& Bell, principalmente os trabalhos desenvolvidos pelos professores Eliseu Martins e mais recentemente pela tese de doutoramento apresentada naquela mesma Universidade por Natan Szuster sob o titulo "Análise do Lucro Passível de Distribuição: Uma abordagem reconhecendo a manutenção do Capital da Empresa".

\section{2 - CONCEITUAÇAO BÁSICA}

\section{Lucro}

HICKS (1) apresenta um dos conceitos mais utilizados na teoria econômica, segundo o qual, lucro é "o valor máximo que unia pessoa possa consumir durante unia semana esperando ainda estar tão bem (as well off) no término desta quanto o estava em seu inicio".

Para MARTINS (2) "Crédito é o resultado econômico que retirado da entidade". num período,de forma tal que o patrimônio liquido no final desse período seja exatamente igual ao 
inicial".

Os dois conceitos tomam o lucro como um excedente sobre unia referência que, no caso, MARTINS considera o Patrimônio Liquido. A dificuldade talvez não esteja nessa conceituação e sim na mensuração do lucro.

Mensuração do lucro

A confrontação da receita com as despesas do período talvez seja a forma mais convencional de se medir o lucro contabilmente.

Porém outros critérios são utilizados para apuração do lucro, como sendo um excesso obtido sobre o capital monetário inicial (Custo Histórico e Custo Histórico Corrigido) ou sobre o capital físico inicial (Custo Corrente ou Custo Corrente Corrigido), todos eles chegando a um valor de lucro diferente.

Assim, segundo SZUSTER (3), "o valor do lucro a ser considerado será uma conseqüência da definição do capital que se pretenda manter".

(1) HíCKS, Jam.s R, Value and Capital, Oxford, 1946-p.172.

(2) MARTINS, Bisou. Contribuição à Avaliação do Ativo Intangível. Tese do Doutorado. São Paulo: FEA/USP. 1972-p.52.

(3) SZUSTER, Natan. Análise do Lucro Passível de Distribuição: Uma abordagem reconhecendo a manutenção do capital da Empresa, 1985-p.9.

\section{LUCRO DISTRIBUÍVTEL}

Considerações Iniciais

À distribuição de um dividendo mínimo obrigatório pelas companhias abertas, determinadas pela Lei das Sociedades Por Ações (6404/76) teve como principal objetivo a necessidade de fortalecer o desenvolvimento de um mercado de capitais de risco no Pais como também proteger os acionistas minoritários.

Isso fica evidente na leitura do texto da Exposição de Motivos que encaminhou o Projeto da Lei 6404/76. "O projeto visa, basicamente, a criar a estrutura jurídica necessária ao fortalecimento do mercado de capitais de risco no Pais contudo o estabelecimento de uma sistemática que assegure ao acionista minoritário o respeito a regras definidas e eqüitativas, as quais, sem imobilizar a empresa em suas iniciativas ofereçam atrativos suficientes de segurança e rentabilidade".

$\mathrm{Na}$ consecução desses objetivos as autoridades governamentais preocuparam-se em

Caderno de Estudos nº5, São Paulo, FIPECAFI- Junho/1992 
compatibilizar o dever das empresas de distribuir um dividendo mínimo com a continuidade e o sucesso do negócio.

Nesse aspecto, as disposições da Lei foram flexíveis o suficiente para admitir mais de uni regime de distribuição de dividendo, considerando as disposições estatutárias das companhias.

Essa flexibilidade envolveu, ainda, a questão do dividendo obrigatório e da capacidade financeira das empresas como colocado na "Exposição Justificativa das Principais Inovações do Projeto".

O importante nessas considerações foi que, apesar da preocupação com o cumprimento do dividendo obrigatório, a Lei não deixou de reconhecer a prevalência da auto preservação da empresa sobre os direitos dos acionistas minoritários quando facultou a constituição da Reserva de Lucros a Realizar e desobrigou a companhia da distribuição do dividendo quando este for incompatível com a sua situação financeira. Reconheceu, dessa forma, unia das principais decisões a serem tomadas pelas empresas que é a definição de sua política de distribuição de dividendos.

Essa decisão abrange a avaliação do valor máximo distribuível, o que está ligado ao conceito de manutenção do capital.

Manutenção do Capital

A manutenção do Capital é uma das responsabilidades básicas da administração.

Neste sentido, existem diversas abordagens ao conceito de manutenção do capital, porém, dois conceitos são mais significativos: compra.

a) Manutenção do Capital Monetário, em termos de moeda constante de poder geral de

Para SZUSTER (4), "o conceito monetário considera o total do valor investido pelos acionistas na empresa como o capital necessário de ser mantido". Este conceito é tido como consistente com o objetivo básico do investidor que deseja preservar e incrementar a forma e a quantidade dos ativos utilizados pela Empresa.

FAVA (5) refere-se à manutenção do Capital Monetário da seguinte forma: "Ocorre à manutenção do Capital Monetário ou Financeiro quando o valor do investimento, expresso em unidades monetárias do final de um período, é igual ou superior ao registrado no inicio do período."

SZUSTER e FAVA consideram o conceito de Capital Monetário separado em duas concepções: o conceito de capital financeiro e o conceito de capital monetário corrigido.

A esse respeito FAVA (6) diz: "Faz-se a seguinte distinção entre capital financeiro e monetário: no primeiro não é reconhecida a variação do poder aquisitivo geral da moeda enquanto que, para determinação da manutenção do capital monetário, efetua-se a correção dos investimentos pelo índice geral de preços." aplicado.

b) Manutenção do Capital Físico, em termos da natureza física dos itens em que foi

Segundo SZUSTER (7) "O conceito de capital físico admite que o patrimônio da empresa

Caderno de Estudos nº5, São Paulo, FIPECAFI- Junho/1992 
é quantificado em termos de uma capacidade de operação, medida através do conjunto de bens necessários a esta, mensurados à data da avaliação. Só haverá lucro quando o patrimônio for superior ao valor dos ativos necessários para assegurar um mesmo nível de atividade. É coerente com o raciocínio de que a empresa permanece em atividade devendo, para tanto, efetuar a reposição de seus ativos. A existência deste conceito é independente da ocorrência da inflação".

FAVA (8) identifica a ocorrência da manutenção do capital físico quando, ao final de um período, a capacidade de produção e distribuição da empresa é igual ou superior a do inicio. A avaliação dos ativos, com base no custo de reposição, é básica para a apuração do investimento de acordo com este conceito. Também neste caso, os valores devem estar expressos em moeda de unia data-base, de forma a possibilitar a comparação dos valores de dois períodos.

A manutenção de uni mesmo nível de atividade pode não significar a manutenção de uni mesmo nível monetário.

As duas abordagens têm seus defensores:

ALLEN (9) argumenta, na defesa da manutenção do capital monetário: "Se o capital representa uni consumo postecipado, está claro que o que precisa ser mantido é o seu poder aquisitivo. Os investidores não estão diretamente interessados em conhecer as variações especificas de preços de itens utilizados pela Empresa. Ao efetuar comparações entre empresas, certamente aplicará algum índice geral de inflação para atualizar o Patrimônio Liquido. Se, por exemplo, unia empresa utiliza-se de mercadorias que subiram de preço mais do que a inflação do período, sua manutenção em quantidade física, na verdade, implica numa expansão real no nível dos ativos da empresa'.

A manutenção do Capital Físico representa a manutenção da capacidade operacional inicial, permitindo a continuidade da empresa, porém, sua aplicação prática é dificultada pela multiplicidade de alterações que podem acontecer nos métodos de produção, nas linhas de produto, na inclusão de novas tecnologias e no próprio mercado, envolvendo necessidades de capital.

Já a manutenção do Capital Monetário tem urna identidade maior com a Contabilidade.

SZUSTER (10) antes de escolher uma das duas alternativas, desenvolveu o seu modelo considerando ambas, de uma forma combinada, na pressuposição de que os dois conceitos têm sua lógica se aplicados a determinados aspectos da vida de uma empresa.

$\mathrm{Na}$ verdade, a compatibilização das duas abordagens é necessária, não cabendo um enfoque exclusivo em um dos conceitos. A distinção entre o que é distribuição de lucro e o que é devolução do capital investido é que deverá ser feita.

Ocorrendo urna situação em que o Capital Físico a ser mantido seja maior do que o Capital Monetário Corrigido o lucro só deverá ser considerado passível de distribuição depois de observada à manutenção da sua capacidade operacional.

$\mathrm{Na}$ ocorrência de uni Capital Monetário Corrigido superior à manutenção da Capacidade Física, o cálculo do Lucro Distribuível deve ser feito com cautela pois se pode contundir o que é devolução de capital a parte não necessária à manutenção da capacidade operacional e o lucro distribuível propriamente dito.

A esse respeito MARTINS (1) efetuou também uma análise comparativa dos conceitos de manutenção do capital, onde expõe de urna forma bastante interessante, dentre outras 
abordagens, que o conceito de manutenção de capital físico pode confundir lucro com capital.

Essa polarização influência sobremaneira a determinação do lucro considerada passível de distribuição.

(4) SZUSTER, Natan. Analise do Lucro Passível de Distribuição: Uma abordagem reconhecendo a manutenção do capital da Empresa, 1985-p.10-11.

FAVA. Ivete. O Custo de Reposição para Fixação de Preço de Venda algumas análises em situação de 1989-p.33.

inflação função do fluxo financeiro. Dissertação.s de Mestrado. São Paulo: FEA/USP.

FAVA. Ivete. O Custo de Reposição para Fixação de Preço de Venda - algumas análises em situação de

inflação em função do fluxo financeiro.) Dissertação de Mestrado. São Paulo: FEA/USP. 1989.-p.33.

(7) SZUSTER Natan. Análise do Lucro Passível de Distribuição: Uma abordagem reconhecendo a manutenção da capital da Empresa, 1985-p 10-11.

FAVA. Ivete O Custo de Reposição para Fixação de Preço de Venda - ala mas analises em situação de 1989-p.34.

inflação em função do fluxo financeiro. Dissertações de Mestrado. São Pauto: FEA/USP.

(9) ALLEN, David. Funds Flow Management: The Key to Financial Control in inflationary Conditions. London

Heinemann, 1980-p.21.

(10) SZUSTER., Natan. Análise do Lucro Passível de Distribuição: Uma abordagem reconhecendo a manutenção do capital da Empresa, 1985-p.10.

(11) MARTINS, Eliseu. Reposição,Inflação Própria e Inflação Geral. Boletim do Contador (. IBRACON. № 128 e 129.

\section{4 - A TEORIA DE EDWARDS \& EELL}

EDWARDS \& BELL (12) desenvolveram suas teorias a respeito do Lucro Distribuível através da reconciliação de dois conceitos de lucro: Contábil e Econômico, pela reconstrução dos conceitos econômicos geralmente aceitos de lucro.

Foram desenvolvidas em quatro passos:

1) revisão da natureza das decisões de obtenção de lucro das empresas;

2) exame das limitações do lucro econômico para avaliação das decisões;

3) desenvolvimento do conceito de Lucros Realizáveis

4) argumentação no sentido de que esse conceito é objetivo e não subjetivo em sua

Caderno de Estudos nº5, São Paulo, FIPECAFI- Junho/1992 
natureza e não incorre nas mesmas limitações do lucro econômico quando usado na avaliação das decisões.

Para os autores "a responsabilidade crucial do administrador numa economia dinâmica é tomar decisões em face de incertezas". Essas decisões, tomadas no presente mas ao sabor das incertezas futuras, visam obviamente a maximização dos lucros que determinam também a composição dos Ativos a serem administrados.

\section{Maximização do Lucro}

Segundo EDWARDS \& BELL (13) os "Ativos representam as ferramentas que sabiamente usadas em conjunto com os elementos comprados posteriormente, produzirão um lucro. O capital representa um significado corrente de financiamento dessas ferramentas".

No esforço de maximizar lucros as empresas escolhem uma estrutura de ativos, e como financia-los. Esse conjunto significa uma expectativa de geração de lucros. Essa estrutura tem um valor para a empresa que deve ser igual ou maior do que a soma dos ativos individuais, avaliados a valor de mercado, caso contrário seria melhor liquidar a empresa. EDWARDS \& BELL (14) chamaram esse valor de VALOR SUBJETIVO e " se a empresa busca maximizar lucros está claro que ela deve selecionar a composição de Ativos que, aos olhos do administrador, tenha o maior valor subjetivo."

(12) EDWARDS, E. O. \& BELL. P. W., The Theory and Measurement of Business Income. Los Angeles

University of California Press, 1961-p.33.

(13) EDWARDS, E O. \& BELL. P. W., The Theory and Measurement of Business Income. Los Angeles:

Universãty ai California Press, 1961-p.33.

\section{Valor Subjetivo como Critério de Decisão}

O cálculo do valor subjetivo é efetuado através da estimativa dos dividendos futuros descontados a valor presente, com o uso de urna taxa de juros (target rate of interest) selecionados pela empresa, mais o valor futuro, descontado à mesma taxa, do grupo de ativos.

A seleção de alternativas de combinação de Ativos é efetuada com base no valor subjetivo de cada unia delas. A estrutura eleita deve ter um valor subjetivo que iguale ou exceda o valor de mercado dos Ativos envolvidos, que é a expectativa de geração de lucros.

Igualmente, pode a Empresa ser vendida, como um todo, por um valor de mercado acima da soma dos valores de mercado de seus Ativos individualmente. Isso significa que para OS de fora a empresa é vista também como uma produtora de dividendos e a avaliam por um valor que antevê2m acima do valor individual dos Ativos, denominado de Valor de Mercado do Goodwill ou GOODWILL OBJETIVO por EDWARDS \& BELL (15). O excesso do Valor Subjetivo sobre o valor de mercado dos Ativos individuais é denominado de GOODWIIL SUBJETIVO.

O que permitiria as seguintes interpretações: 
1) O Goodwill Subjetivo deve exceder o GoodWill Objetivo ou os proprietários da Empresa ficarão desestimulados a continuar;

2) O Goodwill Subjetivo deve ser positivo ou a Empresa estará fora do negócio;

3) Com esses recursos a Empresa deve escolher uni plano cujo Valor Subjetivo ( ou também o GoodWIII Subjetivo) seja o maior;

4) Se a empresa pode emprestar seus recursos a uma taxa de juros de mercado, esses recursos por outro lado não são limitados e um plano com o máximo de

Goodwill Subjetivo será mais rentável. O que pode ser visto como se o item 3 fosse um caso especial do item 4. Ou seja, a maximização do Goodwill Subjetivo é uni critério Geral de escolha entre alternativas.

(14) EDWARDS, E. O. \& BELL. P. W., the Theory and Measurement of Business Income. Los Angeles: University of

California Press, 1961-p.34-35.

(15) EDWASDS, E O. \& BELL. P. W., the Theory and Measurement of Business Income. Los Angeles: University of

California Press. 1961-p.37.

\section{LUCRO SUBJETIVO}

Lucro Subjetivo é o montante que poderia ser dispendido como dividendo em qualquer período sem afetar o Valor Subjetivo.

Foi assim chamado por EDWARDS \& BELL (16) por ser derivado diretamente do conhecimento do Valor Subjetivo e da taxa de juros usada para desconto.

Esse valor também é tido pelos autores como o dividendo que poderia ser pago periodicamente e para sempre, através da retenção e aplicação de parcelas excedentes de receita anual sobre os dividendos estabelecidos e, depois de esgotada a capacidade da máquina em gerar lucros, extraídos dos juros e principal aplicados.

De acordo com a interpretação dos autores, o lucro subjetivo não é o conceito ideal de mensuração contábil porque:

1) não pode ser mensurado objetivamente;

2) apesar de sua mensuração subjetiva, normalmente não pode ser encontrado até que o plano de operações da firma esteja revisado.

Formulação de uma alternativa - Lucros Realizáveis

Segundo os autores "o valor subjetivo de uma firma representa unia lista de eventos subjetivos. O valor de mercado de seus ativos, mais particularmente as mudanças nesses ativos, representam eventos objetivos. A mensuração das mudanças no valor de mercado pode ser 
realizada, ao menos teoricamente, em bases objetivas e não dependentes de estimativas subjetivas". Com base nessas premissas foram definidos os conceitos de Lucros Realizáveis.

O Lucro Realizável Esperado foi definido como o valor que a firma pode pagar como dividendo sem prejudicar o valor de mercado de seus ativos.

Para os autores o Lucro Realizável tem 3 características principais:

1) é objetivo

2) é uma medida justa das mudanças no valor de mercado da firma e

3) seu uso para determinar o pagamento de dividendos permite que o goodwill subjetivo seja distribuído do durante o período de vida do plano de operação.

O lucro realizável e o valor subjetivo da empresa estão relacionados, porque há um "custo" que é omitido no cômputo do lucro realizável. A empresa, ao manter os recursos vinculados às suas atividades operacionais, sacrifica um juro que poderia ganhar, convertendo seus ativos em dinheiro e aplicando-o em títulos, por exemplo. Isto é, o lucro realizável contém dentro de si um custo de oportunidade.

O significado mais comum de goodwill subjetivo é de que este representa o valor presente dos lucros acima do normal (superlucros). EDWARDS \& BELL definem lucro acima do normal como sendo o excesso de lucro realizável.

A relação existente entre o lucro realizável e $O$ goodwill subjetivo pode ser generalizada, se considerarmOS que o valor subjetivo da empresa corresponde ao fluxo de dividendos futuros, descontados a valor presente através de uma taxa de juros escolhida("target rate"), mais o valor de mercado da empresa que remanescer no horizonte, também descontado a valor presente.

(16) EDWARDS, E. O. \& BELL.. P. W., The theorv and Measurement of Business Income. Los Angeles: University 01 California Press, 1961-p.38.

\section{Considerações Sobre o Método}

O modelo desenvolvido pelos autores teve o grande mérito de, além da visão completa de todas as situações que envolvem a distribuição de lucros, iniciar um ciclo produtivo de debates e estudos que introduziram a discussão sobre os critérios de avaliação de Ativos e Passivos.

O desenvolvimento do modelo com base no Valor Subjetivo que, se mantido, permitiria a continuidade da Empresa através da distribuição do Lucro Subjetivo, foi montado apenas no aspecto da Manutenção do Capital Físico da Empresa.

\section{5 - O MODELO DE BZUSTER}

O modelo proposto por Natan Szuster em sua Tese de Doutoramento teve sua base conceitual na manutenção tanto da capacidade física como monetária da Empresa.

Considerou, também, que a estrutura de capital da empresa tem uma influência significativa na manutenção da Capacidade Física, no que se refere à capacidade financiada por recursos próprios, esse aspecto também foi considerado na montagem do modelo, onde, segundo 
o autor, foi admitido que não existe preocupação com a manutenção do nível do Passivo e que à parte da Capacidade Física financiada por recursos de terceiros, quando reposto, serão financiados de forma integral por novos Passivos ou aumento de Capital

O seu desenvolvimento tem inicio na adaptação da Demonstração do Resultado e do Balanço patrimonial resultante da aplicação do método do Custo Corrente corrigido, onde o autor inclui , na ordem de apresentação da Demonstração do Resultado, o conceito de LUCRO—BASE, que se constituí num parâmetro para análise do LUCRO DISTRIBUÍVEL MÁXIMO (LDM).

A Demonstração do Resultado, elaborada segundo o método do Custo Corrente Corrigido, teria a seguinte conformação:

\section{DEMONSTRACÂO DO RESULTADO DO EXERCÍCIO}

Vendas liquidas

(-) Custo das Mercadorias Vendidas

(=) Resultado Bruto Corrente Corrigido

(-) Despesas Operacionais

$( \pm) \quad$ Outras Receitas e Despesas

(+) Ganhos sobre Passivos Monetários

(-) Perdas sobre Ativos Monetários

(+) Receitas Financeiras Liquida

(-) Despesas Financeiras Liquida

(-) Imposto de Renda

$(=) \quad$ Lucro Base

$( \pm) \quad$ Economias (Deseconomias) de Custo Realizadas

$(=) \quad$ Lucro Realizado

$( \pm) \quad$ Ganhos (Perdas) de Estocagem e de Capital não Realizados

(=) Resultado liquido Corrente Atualizado

Após a elaboração dessa Demonstração do Resultado e do Balanço, pelo método do Custo Corrente Corrigidos, adaptados, efetua-se o cálculo do VALOR PASSíVEL DE DISTRIBUIÇÃO, que se constitui no parâmetro de determinação do valor máximo a ser distribuído como dividendos e que manterá intacto o poder aquisitivo da Capacidade Produtiva do Capital da Empresa.

O cálculo do VALOR PASSÍVEL DE DISTRIBUIÇAO (VPD) é feito pelo confronto entre o Patrimônio Liquido corrente na data do Balanço e o valor do Ativo Líquido, na data do Balanço Inicial, em moeda da data do Balanço de Encerramento.

O Ativo Líquido corresponde á capacidade física a ser mantida, financiada por recursos próprios, ou seja, determina-se o total dos Ativos a serem mantidos e deduz-se a parcela correspondente ao Passivo. 
Após o cálculo do VPD calcula-se a variação entre este e o LUCRO-BASE encontrado na Demonstração do Resultado,pelO método do Custo Corrente corrigido.

Num passo seguinte, efetua-se a conciliação entre o VPD e o LUCRO-BASE, que seria a base de justificação da necessidade de retenções ou liberações de lucros, chegando-se ao LUCRO DISTRIBUZVEL MÁXIMO (LDM).

Essa conciliação evidenciará as causas da diferença entre os dois parâmetros, que devem ser explicados e analisados não só para verificação da exatidão dos cálculos como também para justificar as necessidades de retenção ou liberação de lucros.

A esse respeito, PIMENTEL (17) em sua Tese de Doutoramento, analisa com profundidade as variações que compõem a diferença entre o LUCRO-BASE e o VALOR PASSIVEL DE DISTRIBUIÇÃO, pela verificação da composição dos itens não-monetários integrantes da Capacidade Operacional, obtendo os ajustes de conciliação que ajustarão o LUCRO DISTRIBUíVEL MÁXIMO.

\section{CONSIDERACÕES SOBRE O MÉTODO}

O autor desenvolveu vários exemplos, com situações que ocorrem na empresa, buscando evidenciar a aplicação prática do seu método. Algumas situações abordadas foram as seguintes:

- Aumento de Capital no período;

- Custo Corrente do Ativo integrante da capacidade com unia variação de Preços inferior ao IGP do período-análise nos Estoques;

- Ativo Imobilizado Depreciável;

- Venda de Estoques efetuados a prazo.

Todas essas situações exigem ajustes diferenciados para a conciliação entre o Valor Passível de Distribuição e o LUCRO-BASE e ajustarão o Lucro Distribuível Máximo, podendo ser tratadas utilizando-se a metodologia desenvolvida, gerando informações à Administração da Empresa, que poderá, então, elaborar a proposta de distribuição de dividendos, mantendo a continuidade e as capacidades física e financeira da Empresa.

Embora o modelo signifique um grande avanço na evidenciação de informações, algumas dificuldades operacionais existirão, principalmente no que se refere à definição da capacidade física a ser mantida.

Com a crescente evolução tecnológica e o dinamismo dos mercados, a simples manutenção da capacidade existente não seria suficiente à continuidade da Empresa. Porém, esse aspecto também poderia ser considerado como novos investimentos e tratado como um aporte de Capital. 
Outro aspecto relevante é a manutenção do nível de endividamento implicitamente considerado no modelo, quando na realidade existe urna amortização gradual, a menos que se admita urna renovação constante desses Empréstimos.

O modelo desenvolvido por Szuster apresenta grande evolução em relação à teoria da EDWARDS \& BELL, principalmente por considerar também a manutenção do capital monetário, reconciliando os valores dos ganhos e perdas por estocage $3 n$ de fatores que variam diferentemente da inflação.

(17) PIMENTEL. Joede da Silva Contribuição Avaliação Contábil do Lucro Passível de Distribuição. Tese

de Doutorado. São Paulo: FEA/USP. 1986-p.58-90.

\section{6- A PROPOSIÇÃO DE UMA NOVA AEORDAGEM DE CÁlCULO DO LUCRO} DISTRIBUÍVEL FEITA POR PIMENTEL

A proposição de PIMENTEL (18) considera que, apesar da grande melhoria no nível de informação proporcionada pelo método do Custo Corrente Corrigido, existia a necessidade do desenvolvimento de uma nova abordagem para o cálculo do Lucro Distribuível de forma a contornar as dificuldades de interpretação dos Ganhos e Perdas sobre os valores futuros, assim como os artificialismos conceituais a que está sujeito o reconhecimento dos efeitos da inflação, situação que se complica quando se introduz o resultado de subsidiárias no exterior.

Assim, sugere o autor a adoção do "Método Temporal" de Conversão Monetária para a mensuração da grandeza patrimonial das empresas.

Ao rever vários critérios de avaliação de Ativos e Passivos, que repercutem diretamente na mensuração dos resultados das empresas, o autor revela que ao aplicarmos um índice de preços para reajustar o valor de um elemento patrimonial, na verdade estamos fazendo a conversão de uma unidade de medida de natureza monetária para uma unidade de medida de natureza física (poder de compra da moeda, representada pelos bens e serviços que ela pode adquirir).

Para PIMENTEL, todo processo de conversão de unia medida para outra deve ser neutro e não alterar a natureza do objeto medido. Assim, um método de conversão monetária que preserve os critérios de avaliação utilizados pela empresa deveria ser o ideal.

Nasceu daí a idéia de se utilizar do Método Temporal para a conversão monetária dos valores atribuídos aos componentes patrimoniais.

\section{CONSIDERACÕES SOBRE O METODO}

A proposição de PIMENTEL preserva os princípios fundamentais do modelo de SZUSTER com relação á estrutura de apuração do valor do Lucro Distribuível. O ponto principal abordado concentra-se nos critérios de avaliação de Ativos e Passivos onde o autor defende a adoção do Método Temporal comumente utilizado na conversão de Demonstrações Financeiras em outra 
moeda para a moeda local.

A não ser que utilizemos a taxa de paridade pura da moeda, o Método Temporal também apresenta artificialismos vinculados à taxa de conversão utilizada.

(18) PIMENTEL. Joede da Silva. Contribuição ao Estudo da Avaliação Contábil do Lucro Passível de Distribuição. Tese de Doutorado. São Paulo: FEA/USP, 1986-p.248-307.

\section{7 - CONCLUSÃO}

O objetivo principal da Lei 6404/76 foi criar uma estrutura básica para o fortalecimento do mercado de capitais de risco no Pais, com o estabelecimento de regras que propiciassem a mobilização da poupança popular e o seu encaminhamento voluntário para a capitalização das Empresas.

No entanto o desenvolvimento desse mercado teve o seu curso priorizando mais o especulador do que um mercado voltado à capitalização das Empresas. O futuro desse mercado envolve uma participação acionária mais segura com a participação minoritária tendo um peso preponderante.

Espera-se unia mudança nesse comportamento, com um movimento de fundos voltado para investimentos de longo prazo onde o fluxo de dividendos tenha um peso maior nas avaliações do mercado.

Essas avaliações envolveriam a verificação do Lucro Distribuível em comparação com o fluxo de dividendos praticado pelas Empresas, visando a própria segurança do investimento.

A análise do lucro distribuível está vinculada à manutenção do capital, objetivo básico da Empresa e sua própria sobrevivência.

Os conceitos de Manutenção do Capital nos levaram ao exame do Lucro Distribuível sob dois aspectos:

- da Manutenção do Capital Físico, e

- da Manutenção do Capital Monetário.

A abordagem de EDWAR.DS \& BELL foi construída sobre o conceito de Manutenção do Capital Físico levando em consideração o financiamento próprio e o tratamento das vendas somente a vista.

Já SZUSTER considerou os dois conceitos de manutenção do Capital na montagem do seu modelo, o que consistiu num avanço considerável sobre o trabalho precursor sobre o assunto.

Inegavelmente os dois aspectos de manutenção do capital devem ser considerados pois a Empresa deve ter como objetivo

a manutenção de sua capacidade física ou operacional e também preservar o seu capital em termos monetários. Deve-se portanto, determinar o Lucro Distribuível considerando o mais alto valor de capital. 
Outros trabalhos, também relevantes, foram apenas citados, apesar de merecerem urna análise conjunta, pois abordam aspectos complementares à Determinação do Lucro Distribuível.

Esse assunto é por demais vasto e relevante, procuramos abordar apenas os aspectos iniciais que formaram a base do desenvolvimento desse assunto no âmbito da Contabilidade.

\section{8 - REFERÊNCIAS BIBLIOGRÁFICAS}

ALLEN, David. Funds Flow Management: The Key to Financial Control ini Inflationary Conditions. London: Heinemann, 1980.

EDUARDS, E. O. \& BELL, P. W., The Theory and Measurement of Business Income. Los Angeles: University

of California Press, 1973.

FAVA, Ivete. O Custo de reposição cara Fixação de Preço de Venda - algumas análises em situação de 1989.

inflação em função do fluxo financeiro. Dissertação de Mestrado. São Paulo: FEA/USP.

HICKS, James R., Value and Capital, Oxtord, 1946

MARTINS, Eliseu. Contribuição à Avaliação do Ativo Intangível. Tese de Doutorado. São Paulo: FEA/USP,

1972

Reposição. Inflação Própria e Inflação Geral. Boletim do Contador. IBRACON, n9 128 e 129 (jan e fev/89).

MONTEIRO, Deny da Rocha. Lucros a se Realizarem Financeiramente e a Informação Contábil Relevante. Teses de Doutorado. São Paulo: FEA/USP, 1986.

PIMENTEL, Joede da Silva. Contribuição ao Estudo da Avaliação Contábil do Lucro Passível de Distribuição. Tese de Doutorado. São Paulo: FEA/USP. 1986.

SZUSTER, Natan. Análise do Lucro Passível de Distribuição:

Uma abordagem reconhecendo a manutenção do capital da Empresa. Tese de Doutorado. São Paulo: FEA/USP, 1985. 